\title{
Microbial electrochemical monitoring of volatile fatty acids during anaerobic digestion
}

\author{
Jin, Xiangdan; Angelidaki, Irini; Zhang, Yifeng
}

Published in:

Environmental Science \& Technology (Washington)

Link to article, DOI:

10.1021/acs.est.5b05267

Publication date:

2016

Document Version

Peer reviewed version

Link back to DTU Orbit

Citation (APA):

Jin, X., Angelidaki, I., \& Zhang, Y. (2016). Microbial electrochemical monitoring of volatile fatty acids during anaerobic digestion. Environmental Science \& Technology (Washington), 50(8), 4422-4429.

https://doi.org/10.1021/acs.est.5b05267

\section{General rights}

Copyright and moral rights for the publications made accessible in the public portal are retained by the authors and/or other copyright owners and it is a condition of accessing publications that users recognise and abide by the legal requirements associated with these rights.

- Users may download and print one copy of any publication from the public portal for the purpose of private study or research.

- You may not further distribute the material or use it for any profit-making activity or commercial gain

- You may freely distribute the URL identifying the publication in the public portal

If you believe that this document breaches copyright please contact us providing details, and we will remove access to the work immediately and investigate your claim 


\section{Article}

Subscriber access provided by DTU Library

\section{Microbial electrochemical monitoring of volatile fatty acids during anaerobic digestion}

Xiangdan Jin, Irini Angelidaki, and Yifeng Zhang

Environ. Sci. Technol., Just Accepted Manuscript • DOI: 10.1021/acs.est.5b05267 • Publication Date (Web): 30 Mar 2016

Downloaded from http://pubs.acs.org on March 31, 2016

\section{Just Accepted}

"Just Accepted" manuscripts have been peer-reviewed and accepted for publication. They are posted online prior to technical editing, formatting for publication and author proofing. The American Chemical Society provides "Just Accepted" as a free service to the research community to expedite the dissemination of scientific material as soon as possible after acceptance. "Just Accepted" manuscripts appear in full in PDF format accompanied by an HTML abstract. "Just Accepted" manuscripts have been fully peer reviewed, but should not be considered the official version of record. They are accessible to all readers and citable by the Digital Object Identifier (DOI®). "Just Accepted" is an optional service offered to authors. Therefore, the "Just Accepted" Web site may not include all articles that will be published in the journal. After a manuscript is technically edited and formatted, it will be removed from the "Just Accepted" Web site and published as an ASAP article. Note that technical editing may introduce minor changes to the manuscript text and/or graphics which could affect content, and all legal disclaimers and ethical guidelines that apply to the journal pertain. ACS cannot be held responsible for errors or consequences arising from the use of information contained in these "Just Accepted" manuscripts. 
$6 \quad *$ Corresponding author:

7 Dr. Yifeng Zhang

8 Department of Environmental Engineering, Technical University of Denmark, Denmark

$9 \quad$ Tel: $(+45) 45251410$

10 Fax: $(+45) 45933850$

11 E-mail address: yifz@env.dtu.dk 


\section{Abstract}

14 Volatile fatty acid (VFA) concentration is known as an important indicator to control and 15 optimize anaerobic digestion (AD) process. In this study, an innovative VFA biosensor was 16 developed based on the principle of a microbial desalination cell. The correlation between 17 current densities and VFA concentrations was firstly evaluated with synthetic digestate. Two 18 linear relationships were observed between current densities and VFA levels from 1 to $30 \mathrm{mM}$ $19\left(0.04\right.$ to $\left.8.50 \mathrm{~mA} / \mathrm{m}^{2}, \mathrm{R}^{2}=0.97\right)$ and then from 30 to $200 \mathrm{mM}\left(8.50\right.$ to $\left.10.80 \mathrm{~mA} / \mathrm{m}^{2}, \mathrm{R}^{2}=0.95\right)$.

20 The detection range was much broader than that of other existing VFA biosensors. The biosensor 21 had no response to protein and lipid which are frequently found along with VFAs in organic 22 waste streams from AD, suggesting the selective detection of VFAs. The current displayed 23 different responses to VFA levels when different ionic strengths and external resistances were 24 applied, though linear relationships were always observed. Finally, the biosensor was further 25 explored with real AD effluents and the results did not show significance differences with those 26 measured by GC. The simple and efficient biosensor showed promising potential for online, 27 inexpensive and reliable measurement of VFA levels during AD and other anaerobic processes.

28 Key word: Volatile fatty acids; Bioelectrochemical system; Biosensor; Anaerobic digestion; 29 Online monitoring 


\section{Introduction}

Countries across the world are devoting to sustainable society by setting ambitious goals for 34 renewable energy supply. For example, Denmark's long-term energy goal is to become 35 independent of fossil fuel utilization by 2050. Therefore, the increasing use of renewable 36 biofuels such as biogas is inevitable for the future. ${ }^{1}$ The objective of achieving optimum biogas 37 production from anaerobic digestion $(\mathrm{AD})$ is challenged by process instability. ${ }^{2}$ Parameters like $38 \mathrm{pH}$, alkalinity, the biogas producing volume and concentrations of methane and $\mathrm{CO}_{2}$ are typical 39 used as online indicators for the full-scale anaerobic reactor's monitoring. However, several investigations have pointed out disadvantages of these parameters as process indicators due to

41 low sensitivity and reliability. ${ }^{3,4}$ Instead, volatile fatty acids (VFAs), products of the 42 fermentation stage and substrates of the methanogenesis stage, have been widely accepted as 43 sensitive and reliable indicators for the AD process, as they will accumulate and reflect the 44 metabolic imbalance when operating parameters suddenly change or inhibitors occur. Indeed AD 45 sensors that have been investigated the recent years, and have tried to correlate their signal to 46 VFA concentrations, e.g. the sensor response to the gas phase concentration, ${ }^{3}$ UV absorption, ${ }^{5}$

47 electricity $^{6}$ and near infrared ${ }^{4}$. Traditional off line methods of the VFA quantitative measurement 48 such as titration ${ }^{7}$, gas chromatographic $(\mathrm{GC})^{8}$, HPLC $^{5}$ and mid-infrared spectroscopy ${ }^{4}$ have been 49 previously reported. However, most of off line methods are time consuming, inaccurate, require 50 of complex equipment and skilled operations. There have been several attempts to develop 51 online sensors via directly detecting VFA concentrations by GC analysis. However, due to 52 difficult preparation of the samples for the GC analysis of the VFA, these methods have not been 
53 easy to implement. ${ }^{8,9}$ Therefore, constructing a more simple, sensitive and accurate VFA sensing 54 device is critical for the AD process monitoring and control.

Over the past decades, bioelectrochemical systems (BESs) such as microbial fuel cell (MFC)

56 based biosensors have attracted great interest due to the unique advantages in the monitoring of 57 water quality (e.g.; COD, BOD, DO and microbial activities) $)^{10,11,12}$ and toxicants (e.g.; $\mathrm{Ni}^{2+}$ and $\left.58 \mathrm{Cu}^{2+}\right)^{13,14,15}$. These sensors exploited the microbial activities which converted chemical energy 59 stored in organic matter to electrical signals. Comparing to conventional off line determining 60 technologies, BES sensors have several advantages including no need of energy and chemicals, 61 environmental-friendly andsustainable. ${ }^{12}$ Recently, the feasibility of MFC as biosensor for 62 monitoring VFAs has been demonstrated. ${ }^{6,16}$ The MFC biosensor responded to specific VFA, 63 since the anodic biofilm was pre-acclimated using specific VFA as the sole substrates. The work 64 indeed broadens the applications of MFC-based sensors. However, several challenges still need 65 to be addressed before field application. Firstly, the microbial community in the pre-acclimated biofilm might be changed or lose its function during long-term operation with actual AD 67 effluents which contain a large number of microorganisms. Secondly, actual AD effluents always 68 contain complex substrates (e.g.; protein and lipid) in addition to VFAs, which might also 69 change the microbial community and reduce the sensitivity of the sensor. Furthermore, the MFC 70 biosensor might finally function as a sensor for total content of organic matter (e.g.; COD) 71 instead of VFAs, since nearly all kinds of organic matter could be used as substrates in the 72 anode. $^{17}$ Thus, a compact microbial electrochemical system that can avoid the aforementioned 73 challenges should be pursued.

74 In this study, we proposed an innovative bioelectrochemical VFA biosensor on the basis of 75 the microbial desalination cell (MDC). To date, the MDC-liked reactor has never been applied as 
76 a VFA biosensor. The biosensor has three chambers and waste streams containing VFAs were

77 dosed into the middle chamber. Ionized VFAs could transport into the anode chamber through an

78 anion exchange membrane (AEM) which separates the anode and middle chambers and then be

79 utilized by exoelectrogens on the anode electrode for producing electrons. Thus, the current

80 generated might be only proportional to VFA concentrations in the solution of the middle

81 chamber. The transportation of other complex organic matter such as lipid and protein to the

82 anode could be avoided, since most of them are in non-ionic form, and thus, their interference

83 with VFA monitoring could be eliminated. Furthermore, the microbial community in the anode

84 will not be affected by the diverse microorganisms in the AD effluents, since they are separated

85 in two chambers. The objective of this work is to demonstrate the feasibility of the biosensor as

86 simple, sensitive and reliable sensor for monitoring of VFAs. The performance of the biosensor

87 was evaluated in terms of the VFA detection range, sensitivity and reproducibility. The effect of

88 different operating parameters (ionic strength, anion species and external resistance) on the

89 performance of the biosensor was also investigated. Then the reliability of the biosensor was

90 verified with actual AD effluents. The simple biosensor showed promising potential for direct,

91 sensitive, reliable, inexpensive and online VFA monitoring. The outcomes offer a powerful tool

92 for cost-effective monitoring and optimization of $\mathrm{AD}$ process and expand the application of 93 microbial electrochemical system.

95 Material and methods

96

97 Biosensor configuration and operation. Two three-chamber bioelectrochemical reactors (made 98 of nonconductive polycarbonate plates) were used in our present study. The rectangular 
compartments of the fuel cell (anode, middle and cathode chambers) with equal dimension size $(8 \mathrm{~cm} \times 8 \mathrm{~cm} \times 4 \mathrm{~cm}$ ) were physically separated by an AEM (AMI 7001, Membrane international, NJ) and a cation exchange membrane (CEM, CMI 7000, Membrane international, NJ) (Fig. 1). Rubber gaskets and screws were used to tighten the reactors to avoid leakages. The anode electrode was made of a carbon brush $6.0 \mathrm{~cm}$ in diameter and $6.0 \mathrm{~cm}$ in length (Mill-Rose, USA). The cathode electrode was a stainless mesh with an area of $54.8 \mathrm{~cm}^{2}$ (The Mesh Company, UK). Plastic tubes were inserted for medium filling and liquid sampling. The anode and cathode were connected through a $1000 \Omega$ external resistance except as described.

Enrichment and sensing experiment. To enrich exoelectrogens, the anode electrodes were first inoculated in traditional two-chamber MFC reactors for about two months. During the enrichment period, $250 \mathrm{~mL}$ domestic wastewater collected from a primary clarifier (Lundtofte Wastewater Treatment Plant, Lyngby, Denmark) was used as inoculum. Acetate, butyrate, propionate and formate, each with concentrations of $4 \mathrm{mM}$ were dosed as substrates to acclimate the bacterial consortia. In the cathode, $250 \mathrm{~mL}$ ferricyanide solution $(50 \mathrm{mM})$ was used as the electron acceptor. Ferricyanide was only used in this enrichment period. Every 8 to 10 days the reactors were refilled when the voltage was lower than $50 \mathrm{mV}$. After two months enrichment, the anode electrodes produced maximum $500 \pm 50 \mathrm{mV}$ in voltage reproducibly indicating the formation of mature electrochemically active biofilm on the surface of the anode, which was ready for the sensing experiment.

Before transferring the enriched anode electrode into the three-chamber biosensor, the anode was starved for about 2 days to consume the carbon storage in the bacterial cells (corresponding voltage was below $0.2 \mathrm{mV})$. The whole experiment was operated at room temperature $\left(22 \pm 2{ }^{\circ} \mathrm{C}\right)$ in fed batch mode by conducting each batch test for $5 \mathrm{~h}$. The anode chamber of the biosensor 
122 was fed with a buffer solution containing (in $\mathrm{g} / \mathrm{L}$ of distilled water): $\mathrm{NH}_{4} \mathrm{Cl}, 0.31 ; \mathrm{NaH}_{2} \mathrm{PO}_{4} \cdot \mathrm{H}_{2} \mathrm{O}$, 123 2.69; $\mathrm{Na}_{2} \mathrm{HPO}_{4}, 4.33 ; \mathrm{KCl}, 0.13 ; 12.5 \mathrm{~mL}$ mineral solution and $12.5 \mathrm{~mL}$ vitamin solution ${ }^{18}$. The 124 middle chamber was fed with the synthetic digestate containing the buffer solution and VFAs at 125 different levels. VFAs were mainly composed of acetate, propionate, butyrate and formate at a 126 concentration ratio of 10:2:2:1 to mimic the actual composition in the AD system. The cathode 127 chamber was filled with $0.05 \mathrm{mM} \mathrm{NaCl}$ solution. At the beginning of each batch, the anode and 128 using the magnetic stirrer. All experiments were performed in duplicate.

Electrochemical analyses and calculations. Conductivity and $\mathrm{pH}$ were measured using a CDM 83 conductivity meter (Radiometer) and a PHM 210 pH meter (Radiometer), respectively. TS, VS and $\mathrm{NH}_{4}{ }^{+}-\mathrm{N}$ were measured according to the Standard Method. ${ }^{19}$ Acetate, butyrate, 134 propionate and formate were measured via a GC with FID detection (Agilent 6890). The voltage 135 across the resistance was monitored using a digital multimeter (Model 2700, Keithley 136 Instruments, Inc.; Cleveland, OH, USA) with 30 min intervals. Current was calculated according 137 to ohm's law. Current density was calculated as $i=I / A$, where $I(\mathrm{~mA})$ is the current and $A\left(\mathrm{~m}^{2}\right)$ is 138 the project surface area of the cathode.

\section{Results and Discussion}

The response of current densities to various VFA concentrations. The feasibility of the biosensor was investigated under different VFA concentrations with an external resistance of

$1441000 \Omega$. The current density responses to different VFA concentrations along with the operation 
145 time are shown in Figure 2a. The current density increased with the increasing of initial VFA 146 concentrations. As no substrates were dosed in the anode, current increases could only be 147 explained by the transportation of VFAs through the membrane from the middle chamber. When 1481 and $5 \mathrm{mM}$ VFAs were dosed, the current densities were close to the background level, which 149 could be due to the limited VFA transportation to the anode. When the VFA levels were lower 150 than $60 \mathrm{mM}$, the current densities increased gradually with time and reached to the maximum 151 values $\left(0.04-9.36 \mathrm{~mA} / \mathrm{m}^{2}\right)$ at $5 \mathrm{~h}$. Comparatively, the current density increased more sharply and 152 reached to the maximum stable value in less than 3 hours when the initial VFA concentration 153 was between 120 and $200 \mathrm{mM}$. Thus, the response time of the biosensor was chosen as 5 hours 154 in the following tests. It was also observed that the differences among the maximum stable 155 current densities turned to be lower when the initial VFA levels increased from 30 to $200 \mathrm{mM}$, 156 which suggested the biosensor was approaching saturation at those concentrations of the fuels.

157 The correlation between the current density and the VFA level was established as shown in 158 Figure 2b. Two linear relationships were observed between current densities and VFA levels. 159 The current density first increased linearly with VFA levels from 1 to $30 \mathrm{mM}(0.04 \pm 0.01$ to $\left.1608.50 \pm 0.32 \mathrm{~mA} / \mathrm{m}^{2}, \mathrm{R}^{2}=0.97\right)$ and then from 30 to $200 \mathrm{mM}\left(8.50 \pm 0.32\right.$ to $10.80 \pm 1.26 \mathrm{~mA} / \mathrm{m}^{2}$, $\left.161 \mathrm{R}^{2}=0.95\right)$. During the first linear stage, the slope of the linear model was steep as large 162 increments were achieved when enough VFAs were supplied. The current generation was 163 primarily limited by the substrate concentration. During the second stage the slope of the line 164 was quite flattened. The increments in current densities under high VFA concentrations were not 165 as significant as those under lower VFA concentrations which suggested the effect of substrate 166 on the sensor system was not dominant and the biosensor was nearly saturated at high VFA 167 concentrations. The biosensor was further operated in two successive batches to explore its 

$173 \mathrm{mM}$.

response to dynamic changes of the VFA levels (e.g., increasing/decreasing the VFA concentration and undergoing a starvation period without VFAs present) (Figure S1). It was observed that the biosensor responded immediately to the VFA concentration changes without any lag phase. The biosensor also functioned well after a "starvation period". The above results indicate the feasibility of this biosensor for real time VFA monitoring in the range of 1 to 200

Changes in $\mathbf{p H}$ and conductivity. Figure $3 \mathrm{a}$ shows $\mathrm{pH}$ in the chambers under different VFA 175 concentrations at the end of each batch. $\mathrm{pH}$ in the anode and middle chambers kept stable around 176 7.0 due to the high buffer capacity of the phosphate solution which benefited the microbial 177 activities. $^{21}$ In the cathode, $\mathrm{pH}$ increased from $6.86 \pm 0.08$ to $7.58 \pm 0.06$ along with the VFA 178 concentrations. High current densities under high VFA concentrations meant faster reaction rate, 179 which might accelerate the cathode oxygen reduction with proton and lead to the increase of $\mathrm{pH}$. 180 However, the highest $\mathrm{pH}$ in the cathode chamber was $7.58 \pm 0.05$ at a VFA concentration of 200 $181 \mathrm{mM}$, which was much lower than those achieved in the cathode of MFC reactors. ${ }^{22}$ This is 182 because the batch period was short $(5 \mathrm{~h})$ which avoided a significant increase in $\mathrm{pH}$. Stabilizing $183 \mathrm{pH}$ to desired values in the cathode is helpful to inhibit the potential of alkaline scale formation 184 and membrane fouling.

185 The conductivity in the biosensor under various VFA concentrations at the end of each batch 186 is shown in Figure 3b. The dosed medium in the anode and cathode chambers had stable 187 composition and the conductivities kept at $5.15 \pm 0.12$ and $4.52 \pm 0.23 \mathrm{mS} / \mathrm{cm}$, respectively. At the 188 end of each batch, the conductivity of the anolyte and catholyte increased a little ranging from $1895.51 \pm 1.14$ to $6.15 \pm 0.77 \mathrm{mS} / \mathrm{cm}$ and from $5.31 \pm 0.14$ to $5.98 \pm 0.52 \mathrm{mS} / \mathrm{cm}$, respectively due to 190 ions migration and redox reaction. When the VFA concentration was lower than $30 \mathrm{mM}$, the 
191 conductivities of the synthetic digestate in the middle chamber were below $7.2 \mathrm{mS} / \mathrm{cm}$ and the 192 substrate concentration was more influential on the electricity generation. When the VFA 193 concentrations were above $30 \mathrm{mM}$, the higher VFA concentration increased the substrate to the 194 anode microbial community and the conductivity which together affected the current generation. 195 The conductivity in the synthetic digestate increased from $7.12 \pm 0.89(30 \mathrm{mM})$ to $14.45 \pm 1.81$ $196 \mathrm{mS} / \mathrm{cm}(200 \mathrm{mM})$. The internal resistance would be lowered a little with the minor conductivity 197 increase. $^{23,24}$ The current would be elevated further at higher VFA concentrations which was 198 consistent with the results shown in Figure 2b, where the second positive linear relationship from 199 VFA levels of 30 to $200 \mathrm{mM}$. Thus, the current generation of the biosensor was affected by both 200 201 the substrate concentration and the solution conductivity. Effect of protein and lipid on the biosensor performance. The anodic biofilm in BESs is 202 able to metabolize a variety of organic compounds after a period of adaptation. ${ }^{23}$ Protein and 203 lipid are common organic matter in $\mathrm{AD}$ reactors which can also be utilized as substrates by 204 exoelectrogens on the anode. ${ }^{25}$ The current generation of existing MFC-based VFA sensors 205 would be proportional to all the degradable substrates and the result would be overestimated 206 since samples were dosed into the anode chamber and bacteria could not differentiate between 207 VFAs and other assimilable organic matter. In this study with our BES biosensor, we 208 hypothesize that only anionic substances such as VFAs can transport through the AEM while 209 other non-ionic complex organic matter would be retained. Then the overestimation that was 210 caused due to protein and lipid and other organic molecules on the estimation of the VFA by the 211 biosensor could be eliminated. To prove such hypothesis, $2 \mathrm{~g} / \mathrm{L}$ gelatin and $9.2 \mathrm{~g} / \mathrm{L}$ glyceryle 212 trioleate (GTO), as model of protein and lipid, respectively, were added in the synthetic digestate 213 in the middle chamber of the BES (R1). In a similar reactor, synthetic digestate containing 0.2 
$214 \mathrm{~g} / \mathrm{L}$ gelatin and $0.92 \mathrm{~g} / \mathrm{L}$ GTO was dosed into the anode chamber (C1). The current density of the 215 two BES reactors is shown in Figure 4. The current density in R1 kept below $0.2 \mathrm{~mA} / \mathrm{m}^{2}$ during $21624 \mathrm{~h}$ operation while that in $\mathrm{C} 1$ increased above $8.0 \mathrm{~mA} / \mathrm{m}^{2}$ after $5 \mathrm{~h}$. After $24 \mathrm{~h}$ operation, the 217 detected ammonia nitrogen in $\mathrm{C} 1$ was $0.12 \mathrm{~g}-\mathrm{N} / \mathrm{L}$ suggesting the protein was digested when it 218 was available to the bacteria. The low current density in R1 indicated that gelatin and GTO was 219 retained by AEM effectively. In contrast, ionized VFAs could easily pass through the AEM and 220 were utilized to produce electricity. Overall, the BES biosensor could effectively eliminate the 221 interference of protein and lipid and could monitor the VFA concentrations correctly.

222 Effect of ionic strength and external resistance. To investigate the influence of inorganic 223 ionic substances on the VFA biosensor performance, different concentrations of $\mathrm{NaCl}$ and $224 \mathrm{Na}_{2} \mathrm{SO}_{4}(10,30$ and $100 \mathrm{mM})$ were dosed into the synthetic digestate. The conductivity in the 225 middle chamber, the current density and the accumulated VFA concentrations in the anode 226 chamber after $5 \mathrm{~h}$, as the function to the varying VFA concentrations in the synthetic digestate 227 are displayed in Figure 5. High salinity increased the conductivity and the anion concentration 228 which may compete with VFA species on the transportation via the AEM. Compared to the 229 synthetic digestate without an additional salt, the average increases in conductivity were $45 \%, 78 \%$ 230 and $149 \%$ by adding 10,30 and $100 \mathrm{mM} \mathrm{NaCl}$, respectively. When 10,30 and $100 \mathrm{mM}$ of $231 \mathrm{Na}_{2} \mathrm{SO}_{4}$ were dosed, the conductivity increased by $48 \%, 108 \%$ and $196 \%$ in average, (Figure 5a 232 and 5b). In Figure 5c and 5d, the smallest current densities at the lowest conductivity 233 demonstrated that the increased ionic strength was advantageous for the bioelectricity production.

234 High ionic strength benefited the system by reducing the internal resistance. As shown in Figure $2355 \mathrm{e}$ and 5f, accumulated VFAs in the anode decreased along with salt concentrations. High salt 236 concentrations led to a more competitive migration of $\mathrm{Cl}^{-}$and $\mathrm{SO}_{4}^{2-}$ to balance the charge. 
237 Relatively less ionized VFAs passed through the membrane which played a negative effect on 238 electricity production. Current density increased linearly from $0.06 \pm 0.03$ to $9.37 \pm 0.69 \mathrm{~mA} / \mathrm{m}^{2}$ (1$23930 \mathrm{mM}$ VFAs) and from $9.37 \pm 0.69$ to $11.15 \pm 0.37 \mathrm{~mA} / \mathrm{m}^{2}(30-200 \mathrm{mM} \mathrm{VFAs})$ at $10 \mathrm{mM} \mathrm{NaCl}$. 240 When $30 \mathrm{mM} \mathrm{NaCl}$ was added, the current density increased further from $0.14 \pm 0.08$ to $24112.25 \pm 1.92 \mathrm{~mA} / \mathrm{m}^{2}(1-30 \mathrm{mM}$ VFAs $)$ and from $12.25 \pm 1.92$ to $13.48 \pm 1.32 \mathrm{~mA} / \mathrm{m}^{2}(30-200 \mathrm{mM}$ 242 VFAs). This is because the effect of conductivity was more significant than the competition 243 between inorganic anions and ionized VFA on the biosensor performance. When the salt 244 concentration was further increased to $100 \mathrm{mM}$, the current densities decreased lower than those 245 at $30 \mathrm{mM}$ salt concentration. It could be due to that the high conductivity could not lower the 246 internal resistance much further while the competition on the anionic transportation was 247 enhanced.

248 When the VFA concentration in the synthetic digestate was less than $30 \mathrm{mM}$, the differences 249 in current densities (Figure 5c and 5d) and accumulated VFA concentrations in the anode (Figure 250 5e and 5f) under different salt concentrations were not significant. This is because the substrate 251 was the main limiting factor for current generation compared to ionic strength. The results 252 indicate the biosensor's applicability to the AD processes with varied salinity at VFA levels 253 below $30 \mathrm{mM}$. When enough substrates were supplied, the difference of accumulated VFAs and 254 current densities under varying ionic strength were obvious because ionic strength played a main 255 role. Thus, a calibration would be needed for the samples with high salinity at high VFA levels. 256 In addition to the sensor calibration, the effluent from AD plants treating high salinity 257 wastewaters could be diluted to avoid such interference. At the same concentration, $\mathrm{Na}_{2} \mathrm{SO}_{4}$ 258 rather than $\mathrm{NaCl}$ contributed more in the conductivity increase, which was in line with the 259 steeper slopes in correlation curves between the current densities and VFA concentrations. Less 
260 VFA were accumulated in the anode when $\mathrm{Na}_{2} \mathrm{SO}_{4}$ was added in the synthetic digestate instead 261 of $\mathrm{NaCl}$. It could be due to that more charges can be balanced when the same amount of double262 valent $\mathrm{SO}_{4}{ }^{2-}$ migrated through the membrane compared to monovalent $\mathrm{Cl}^{-}$, with respect to the 263 constant ion exchange capacity of the membrane. In previous report ${ }^{24}$, the high $\mathrm{NaCl}$ 264 concentration was proved to be inhibitory for the anaerobic microorganisms. In our work, the 265 sample was separated from the anode with the AEM which improved the biosensor's ability to 266 resist high salinity. Thus, the biosensor has the potential to monitor AD processes treating high 267 salinity wastewaters. Cations such as ammonium which is one of the important substances in AD 268 reactors were not studies here, as they would transfer toward the cathode and not compete with 269 VFA species on the transportation.

270 Apart from the ionic strength, the external resistance is another factor that has an influence 271 on the electron flow rate, microbial communities and the sensor performance. ${ }^{26}$ Thus, different 272 external resistances $(10,180,518$ and $1000 \Omega)$ were applied in the system to evaluate the impact. 273 The current densities at $5 \mathrm{~h}$ against different VFA concentrations are displayed in Figure 6a. The 274 application of a lower external resistance allowed a relatively higher current density. Two linear 275 relationships were observed between the current density and the VFA concentration for all the 276 tested external resistances. The difference in the current density under different external 277 resistances was much bigger at higher VFA concentrations than that at lower VFA 278 concentrations. This could be due to that the substrate concentration was the main limiting factor 279 for current production at low VFA concentration, while the external resistance became the main 280 limiting parameter at higher VFA concentrations. Lower concentrations of VFA accumulated in 281 the anode at low external resistance as shown in figure 6b. As the same ionic strength and 282 species were applied under all the external resistances, there were no big differences in the 
283 amount of migrated ionized VFAs. However, high current outputs with low external resistances 284 demonstrated fast rates of respiration and more substrate consumption. ${ }^{27}$ So less VFA 285 accumulation was obtained. The results suggested that the external resistance was important for 286 the sensor's sensitivity. Changes in current related to different substrate concentrations will be 287 amplified at low external resistance. However, relatively larger deviations in the current 288 generation were observed with the low external resistance. This might be because the external 289 resistance is close to the internal resistance or even lower than the internal resistance. In this case 290 the internal resistance played a more important role in the system and easily fluctuated with 291 respect to the environmental conditions. Thus, the sensor subjected to environmental changes 292 will be more robust and stable at high external resistance in the long run.

Application in real AD effluent. The BES biosensor was then tested with real AD effluents 294 to verify its applicability. Five samples were taken from four lab-scale AD reactors. The 295 determination of the VFA composition and the operational data of the reactors were given in 296 Table S1 and S2 (Supporting Information). The samples were stored at $4^{\circ} \mathrm{C}$ before used except 297 sample 3 which was stored in the incubator at $55.3^{\circ} \mathrm{C}$ to deplete the substrate. The results 298 obtained from the biosensor (Figure S1) and GC are summarized in Table 1 along with some 299 characteristics of the samples. The values obtained from the biosensor were close to those 300 measured by GC despite the samples with varied VFA compositions and reactor operating 301 conditions. Anova analysis showed negligible difference between the data achieved by our 302 biosensor and $\mathrm{GC}\left(\mathrm{F}=0.90>\mathrm{F}_{(5,4)}=0.16, \mathrm{P}<0.05\right)$ which demonstrated the accuracy of the 303 biosensor. As shown in Figure S2, our biosensor ran stably and sensitively even the samples 304 were fed successively. It can be concluded the biosensor has shown reliable results for detecting 305 the VFA concentration of AD effluents. 
Perspectives. The present work for the first time demonstrated the applicability of the

307

308

309

310

311

312

313

314

315

316

317 innovative three-chambered bioelectrochemical sensor for online VFA monitoring during AD processes. Compared with traditional off line sensing technologies, the novel bioelectrochemical biosensor developed here has several advantages. First, no external power is needed since the reactor can power itself from substrate oxidation, which suggests the suitability for in situ and long-term monitoring. Secondly, there is no need of a signal transducer because the current produced can be directly used as a measurement of the VFA concentrations. Compared to the MFC-based biosensors, the biosensor still has its own merits. The biosensor separated the biofilm and the bulk substrate innovatively which can distinguish VFAs from other complex organic matter; therefore results will be much more reliable. Moreover, the detection range was widened significantly as the bulk solution was dosed in the middle chamber. Thirdly, the AEM can also protect the anodic microbial community from high salinity, inhibitors (e.g.; $\mathrm{NH}_{4}^{+}$) and toxicants (e.g.; metal ions) presented in the AD effluents.

After 7 months operation, reproducible and stable current was achieved without membranes cleaning or replacement which demonstrates the robustness of the biosensor. Moreover, the response of $5 \mathrm{~h}$ is adequate for frequent VFA monitoring in AD reactor systems with relatively long hydraulic retention times which are usually more than 10 days. The response time of our biosensor at present stage is comparable with other described VFA sensors. Further reduction of the response time below 5 hours which is the current response time in our biosensor, could be advantageous in some applications. However, for conventional biogas processes, the response time is more than adequate. Some suggestions for increasing the frequency for VFA monitoring could be to increase the electrical field of the anode and cathode electrodes to accelerate the VFA migration and enhance the voltage output further. Thus, faster equilibrium state could be 
329 achieved with a shorter response time. The response time could be shortened through system

330 optimization (e.g., a new reactor configuration and the electrode modification). This could be

331 needed for AD processes operating at HRTs much lower than a couple of days, which is however,

332 very seldom the case. To further consolidate the application of the biosensor to other anaerobic

333 processes, it would also be interesting to test the biosensor with more different VFA

334 compositions. Besides, the anode solution could be operated in a mode with regular refilling with

335 anodic solution to eliminate the effect of the VFA accumulation on the detection during

336 continuous monitoring. Therefore, supplying an external voltage, minimizing the architecture,

337 modifying the anode and cathode materials, continuous monitoring with different anaerobic

338 processes, shortening the response time and promoting the practical application of the VFA

339 biosensor will be the focus in future works.

\section{Acknowledgement}

The authors would like to acknowledge financial support from the China Scholarship

343 Council and the technical assistance by Hector Gracia with analytical measurements. The authors

344 also thank Xiaohu Li for advice on experiment and thank Ilaria Bassani, Xinyu Zhu and

345 Temesgen Mathewos Fitamo for supplying AD effluents from their reactors. This research was

346 supported financially by The Danish Council for Independent Research (DFF-1335-00142).

\section{Supporting Information Available}

348 Table S1, Table S2, Figure S1 and Figure S2 as noted in the text. This material is available 349 free of charge via the Internet at http://pubs.acs.org/ 


\section{References}

(1) Tonini D.; Astrup T. LCA of biomass-based energy systems: A case study for Denmark. Energy Policy 2013, 61, 829-839.

(2) Ahring, B.K.; Sandberg, M.; Angelidaki, I. Volatile fatty acids as indicators of process imbalance in anaerobic digestors. Appl. Microbiol. Biotechnol. 1995, 43(3), 559-565.

(3) Boe, K.; Batstone, D.J.; Angelidaki, I. An innovative online VFA monitoring system for the anerobic process, based on headspace gas chromatography. Biotechnol Bioeng. 2007, 96(4), $712-$ 721.

(4) Falk, H.M.; Reichling, P.; Andersen, C.; Benz, R. Online monitoring of concentration and dynamics of volatile fatty acids in anaerobic digestion processes with mid-infrared spectroscopy. Bioprocess Biosyst Eng. 2015, 38(2), 237-249.

(5) de Sá, L.R.V.; De Oliveira, M.A.L.; Cammarota, M.C.; Matos, A.; Ferreira-Leitao, V.S. Simultaneous analysis of carbohydrates and volatile fatty acids by HPLC for monitoring fermentative biohydrogen production. Int. J. Hydrogen Energy 2011, 36(23), 15177-15186.

(6) Kaur, A.; Kim, J.R.; Michie, I.; Dinsdale, R.M.; Guwy, A.J.; Premier, G.C.; Sustainable Environment Research, C. 2013. Microbial fuel cell type biosensor for specific volatile fatty acids using acclimated bacterial communities. Biosens Bioelectron. 2013, 47, 50-55.

(7) Purser, B.J.; Thai, S.-M.; Fritz, T.; Esteves, S.; Dinsdale, R.; Guwy, A. An improved titration model reducing over estimation of total volatile fatty acids in anaerobic digestion of energy crop, animal slurry and food waste. Water Res. 2014, 61, 162-170.

(8) Boe, K.; Angelidaki, I. Pilot-scale application of an online VFA sensor for monitoring and control of a manure digester. Water Sci Technol, 2012, 66(11), 2496-2503. 
373 (9) Pind, P.F.; Angelidaki, I.; Ahring, B.K. A new VFA sensor technique for anaerobic reactor systems. Biotechnol Bioeng. 2003, 82(1), 54-61.

375

376

377

378

379

380

381

382

383

384

385

386

387

388

389

390

391

392

393

394

(10) Zhang, Y.; Angelidaki, I. A simple and rapid method for monitoring dissolved oxygen in water with a submersible microbial fuel cell (SBMFC). Biosens. Bioelectron. 2012, 38(1), 189-194.

(11) Zhang, Y.; Angelidaki, I. Submersible microbial fuel cell sensor for monitoring microbial activity and BOD in groundwater: focusing on impact of anodic biofilm on sensor applicability. Biotechnol. Bioeng. 2011, 108(10), 2339-2347.

(12) Zhang, Y.; Min, B.; Huang, L.; Angelidaki, I. Electricity generation and microbial community response to substrate changes in microbial fuel cell. Bioresour. Technol. 2011, 102(2), 1166-1173.

(13) Stein, N.E.; Hamelers, H.M.; van Straten, G.; Keesman, K.J. On-line detection of toxic components using a microbial fuel cell-based biosensor. J. Process Control 2012, 22(9), 1755 1761.

(14) Quek, S.-B.; Cheng, L.; Cord-Ruwisch, R. Detection of low concentration of assimilable organic carbon in seawater prior to reverse osmosis membrane using microbial electrolysis cell biosensor. Desalin. Water Treat. 2014, 55(11) 1-6.

(15) Wang, J.; Zheng, Y.; Jia, H.; Zhang, H. Bioelectricity generation in an integrated system combining microbial fuel cell and tubular membrane reactor: Effects of operation parameters performing a microbial fuel cell-based biosensor for tubular membrane bioreactor. Bioresour. Technol. 2014, 170, 483-490.

(16) Kaur, A.; Ibrahim, S.; Pickett, C.J.; Michie, I.S.; Dinsdale, R.M.; Guwy, A.J.; Premier, G.C. Anode modification to improve the performance of a microbial fuel cell volatile fatty acid biosensor. Sens. Actuators, B 2014, 201, 266-273. 
395
(17) Yang, N.; Hafez, H.; Nakhla, G. Impact of volatile fatty acids on microbial electrolysis cell performance. Bioresour. Technol. 2015, 193, 449-455.

(18) Kvesitadze, G.; Sadunishvili, T.; Dudauri, T.; Zakariashvili, N.; Partskhaladze, G.; Ugrekhelidze, V.; Tsiklauri, G.; Metreveli, B.; Jobava, M. Two-stage anaerobic process for bio-hydrogen and bio-methane combined production from biodegradable solid wastes. Energy 2012, 37(1), 94-102.

(19) APHA, AWWA, WPCF. Standard methods for the examination of water and wastewater, $20^{\text {th }}$ ed.; Wshington, DC, 2000.

(20) Di Lorenzo, M.; Thomson, A.R.; Schneider, K.; Cameron, P.J.; Ieropoulos, I. A small-scale aircathode microbial fuel cell for on-line monitoring of water quality. Biosens. Bioelectron. 2014, 62, 182-188.

(21) He, Z.; Huang, Y.; Manohar, A.K.; Mansfeld, F. Effect of electrolyte pH on the rate of the anodic and cathodic reactions in an air-cathode microbial fuel cell. Bioelectrochemistry 2008, 74(1), 7882.

(22) Mehanna, M.; Kiely, P.D.; Call, D.F.; Logan, B.E. Microbial electrodialysis cell for simultaneous water desalination and hydrogen gas production. Environ. Sci. Technol. 2010, 44(24), 9578-9583.

(23) Du, Z.; Li, H.; Gu, T. A state of the art review on microbial fuel cells: a promising technology for wastewater treatment and bioenergy. Biotechnol. Adv. 2007, 25(5), 464-482.

(24) Lefebvre, O.; Tan, Z.; Kharkwal, S.; Ng, H.Y. Effect of increasing anodic $\mathrm{NaCl}$ concentration on microbial fuel cell performance. Bioresour. Technol. 2012, 112, 336-340.

(25) Elakkiya, E.; Matheswaran, M. Comparison of anodic metabolisms in bioelectricity production during treatment of dairy wastewater in Microbial Fuel Cell. Bioresour. Technol. 2013, 136, 407412. 
417 (26) Jung, S.; Regan, J.M. Influence of external resistance on electrogenesis, methanogenesis, and anode prokaryotic communities in microbial fuel cells. Appl. Environ. Microbial. 2011, 77(2), 564-571.

420 (27) Rismani-Yazdi, H.; Christy, A.D.; Carver, S.M.; Yu, Z.; Dehority, B.A.; Tuovinen, O.H. Effect of external resistance on bacterial diversity and metabolism in cellulose-fed microbial fuel cells.

422 Bioresour. Technol. 2011, 102(1), 278-283.

423

424

425

426

427

428

429

430

431

432

433

434

435

436 
437 Table 1. Determination of VFAs in real AD effluents by the BES sensor and GC and characteristics of 438 the samples

\begin{tabular}{lllllll}
\hline Sample & $\begin{array}{l}\mathrm{VFAs}^{\mathrm{a}} \\
(\mathrm{mM})\end{array}$ & $\begin{array}{l}\mathrm{VFAs}^{\mathrm{b}} \\
(\mathrm{mM})\end{array}$ & $\mathrm{pH}$ & $\begin{array}{l}\text { Conductivity } \\
(\mathrm{mS} / \mathrm{cm})\end{array}$ & TS (g/L) & VS (g/L) \\
\hline 1 & $3.86 \pm 0.73$ & $3.02 \pm 0.06$ & $7.76 \pm 0.1$ & $12.98 \pm 0.24$ & $16.65 \pm 0.03$ & $10.09 \pm 0.02$ \\
2 & $9.32 \pm 0.35$ & $8.83 \pm 0.89$ & $9.01 \pm 0.2$ & $17.16 \pm 0.17$ & $15.16 \pm 0.04$ & $8.01 \pm 0.04$ \\
3 & $0 \pm 0$ & $0.04 \pm 0.02$ & $8.07 \pm 0.2$ & $6.44 \pm 0.12$ & $3.02 \pm 0.04$ & $0.58 \pm 0.03$ \\
4 & $6.25 \pm 0.58$ & $6.67 \pm 0.54$ & $8.55 \pm 0.1$ & $15.09 \pm 0.15$ & $10.27 \pm 0.04$ & $3.76 \pm 0.03$ \\
5 & $35.30 \pm 0.92$ & $36.82 \pm 0.65$ & $7.73 \pm 0.1$ & $9.73 \pm 0.13$ & $16.18 \pm 0.12$ & $11.91 \pm 0.07$
\end{tabular}

$439{ }^{\mathrm{a}}$ Measured by GC method.

$440 \quad{ }^{b}$ Measured by the biosensor.

441

442 


\section{Figure Caption}

444 Figure 1. Sensor prototype (a) and schematic diagram (b). A, the anode chamber; $M$, the middle chamber; membrane.

447 Figure 2. Typical current generation from the biosensor during the batch mode experiment (a) and the relationship between current density and VFA concentrations at $5 \mathrm{~h}(\mathrm{~b})$.

449

450

451

452

453

Figure 3. $\mathrm{pH}$ (a) and conductivity (b) in the bioreactor at $5 \mathrm{~h}$ with various VFA concentrations. Error bars represent the range of duplicate tests.

Figure 4. Current density from the biosensor. R1: $2.0 \mathrm{~g} / \mathrm{L}$ gelatin and $9.2 \mathrm{~g} / \mathrm{L}$ GTO were dosed in the middle chamber; $\mathrm{C} 1: 0.20 \mathrm{~g} / \mathrm{L}$ gelatin and $0.92 \mathrm{~g} / \mathrm{L}$ GTO were dosed in the anode chamber.

Figure 5. The synthetic digestate conductivity in the middle chamber $(a, b)$, the correlation curves between VFA levels and current density $(\mathrm{c}, \mathrm{d})$ and the accumulated VFAs in the anode chamber $(\mathrm{e}, \mathrm{f})$ at $5 \mathrm{~h}$ under different $\mathrm{NaCl}$ and $\mathrm{Na}_{2} \mathrm{SO}_{4}$ concentrations.

Figure 6. The correlation curves between VFA levels and current density (a) and the accumulated VFAs in the anode chamber (b) at $5 \mathrm{~h}$ through different external resistances. 

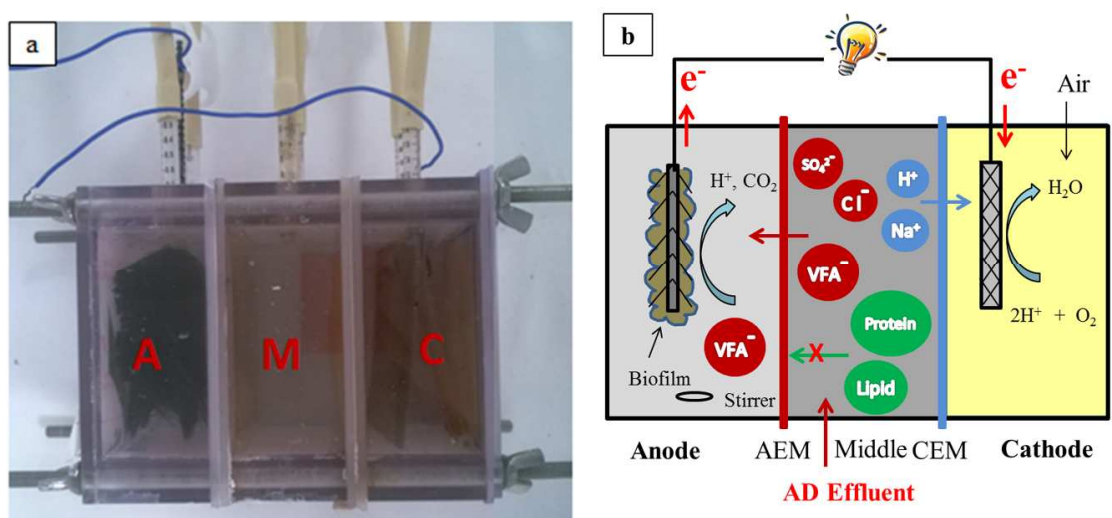

460

461

Figure 1

462 

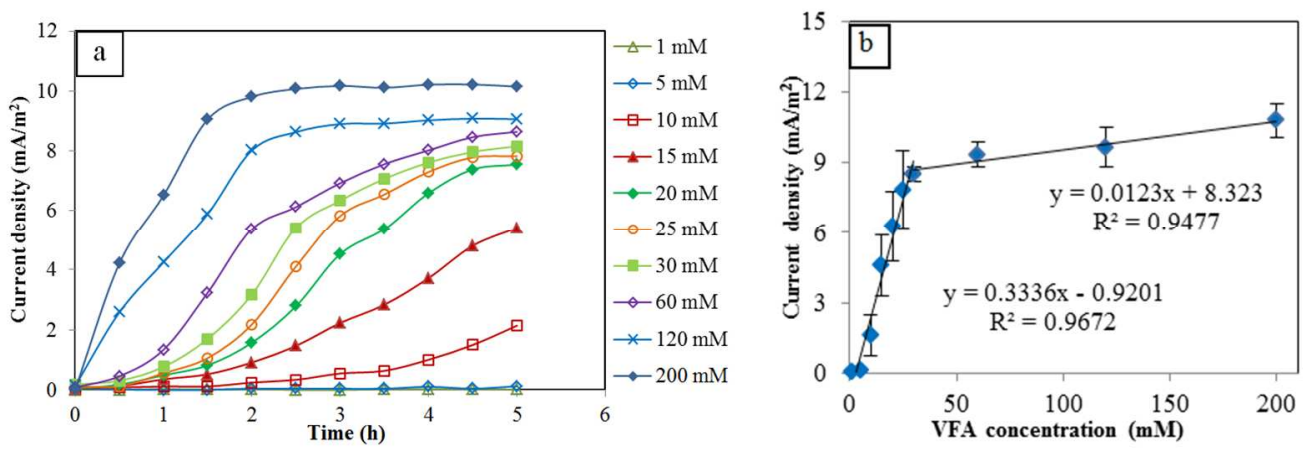

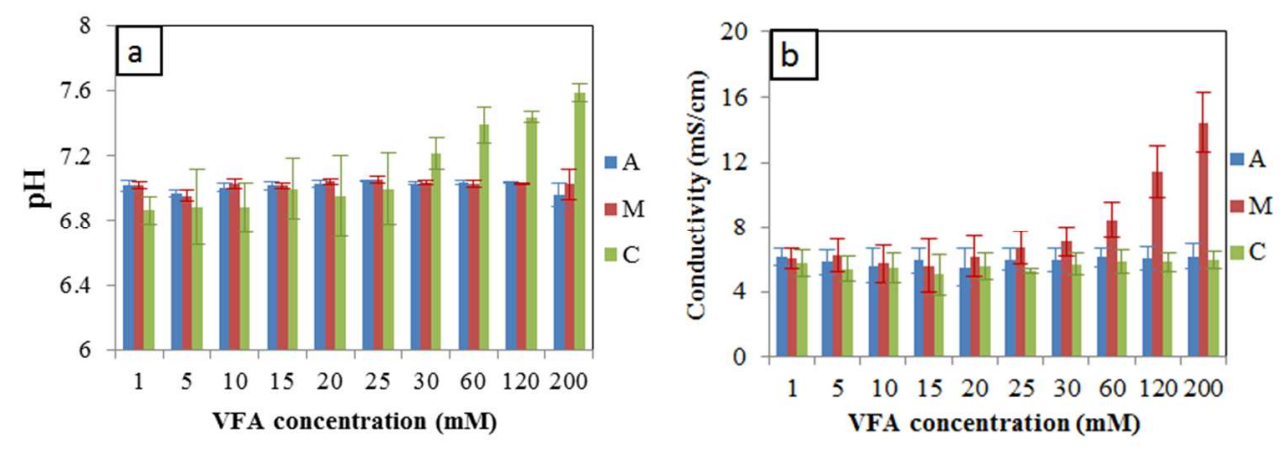

468

469

Figure 3

470 


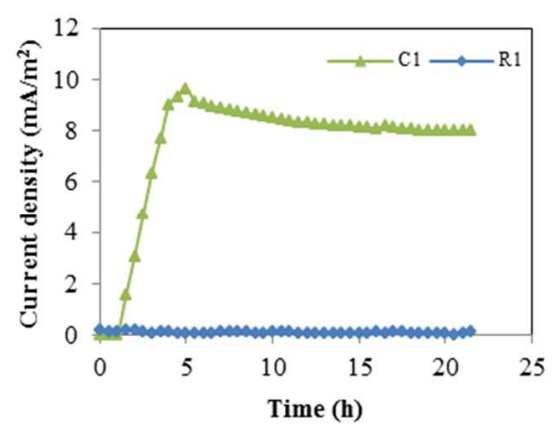

472

473

Figure 4

474 
475
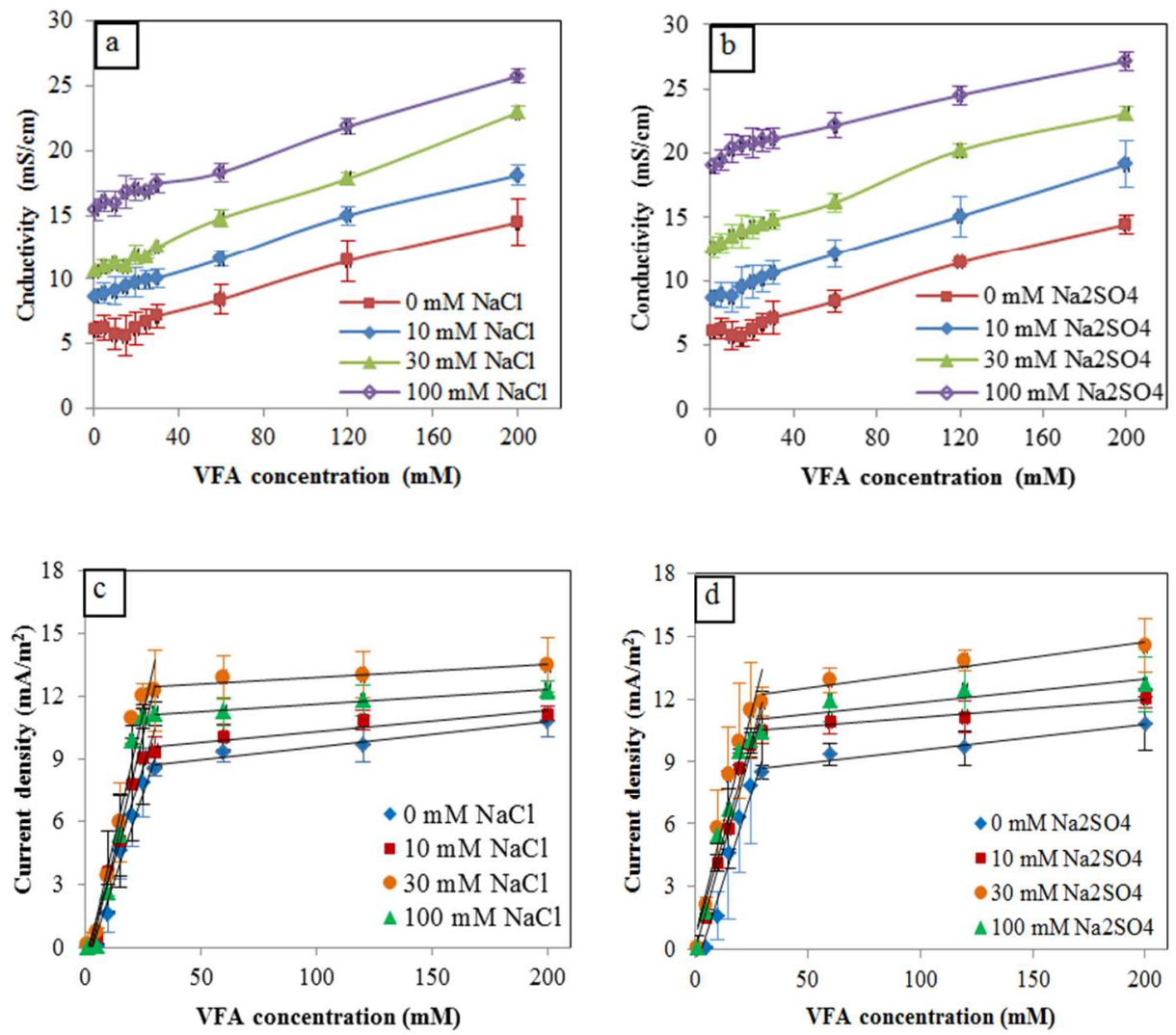

476

VFA concentration (mM)

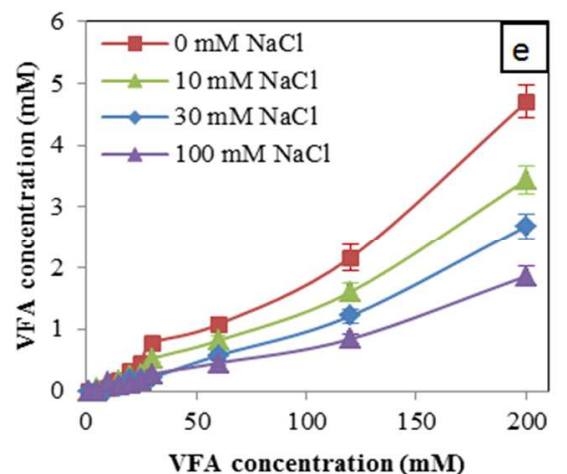

477

VFA concentration (mM)

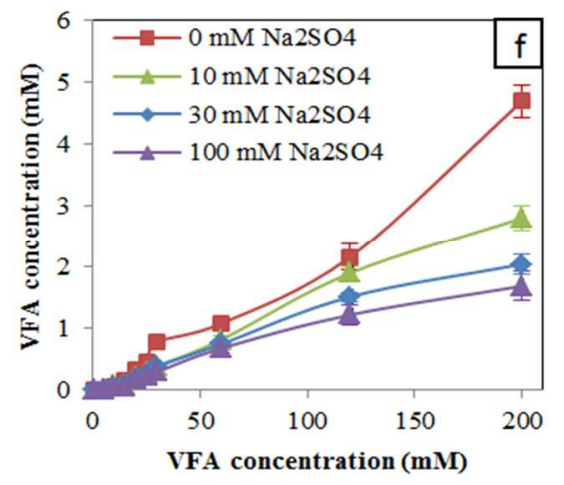

478

Figure 5 

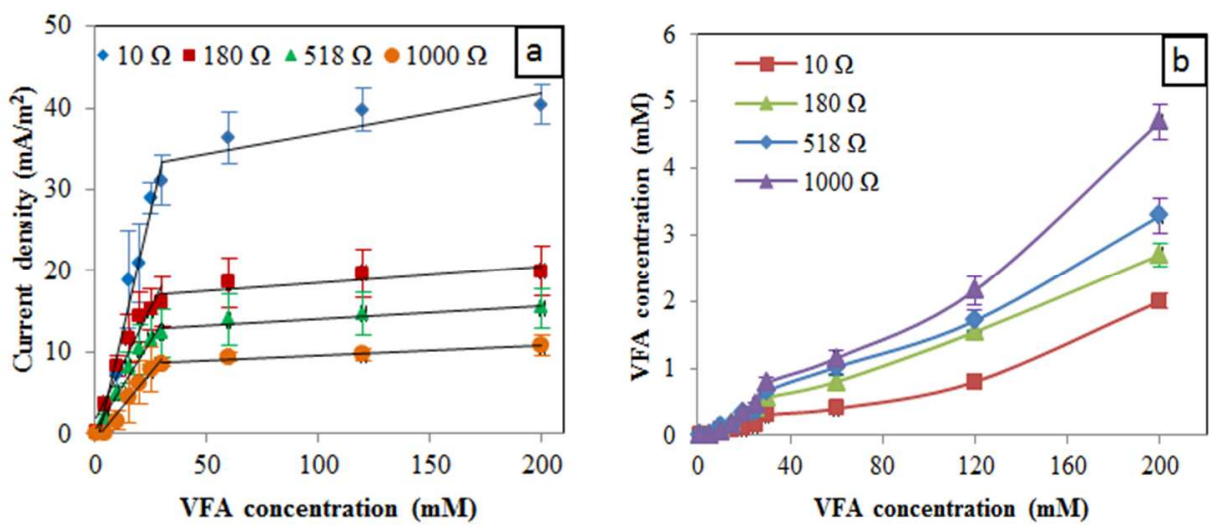

482

484

485

486

487

488

489

490

491

492

493

494

495 


\section{TOC art}

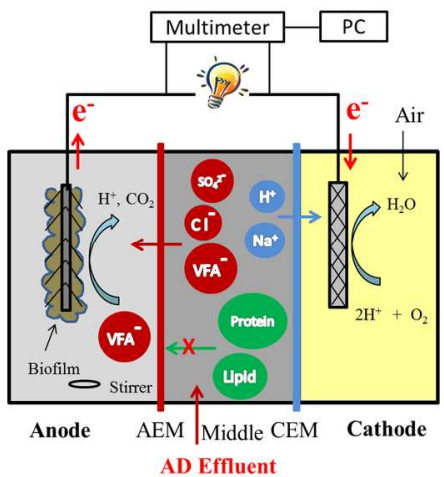

